УДК 378.637

DOI 10.37386/2413-4481-2020-1-49-57

Д.В. Каширский, М.А. Малетина

СПОСОБЫ РАЗРЕШЕНИЯ КОНФЛИКТОВ

СТУДЕНТАМИ ПЕДАГОГИЧЕСКОГО ВУЗА

В ЗАВИСИМОСТИ ОТ ПРОФИЛЯ ОБРАЗОВАНИЯ

И СКЛОННОСТИ К РАЗЛИЧНЫМ ФОРМАМ АГРЕССИВНОГО ПОВЕДЕНИЯ

\begin{abstract}
Представлены результаты исследования способов разрешения конфликтов студентами педвуза в зависимости от профиля обучения и склонности к различным формам агрессивного поведения. Выборку составили студенты ИПиП и ИФКиС Алтайского государственного педагогического университета в возрасте 18-22 лет (50 человек). Установлено, что между группами студентов нет значимых различий в способах разрешения конфликтов и преобладании форм агрессивного поведения. Выявлена зависимость способов разрешения конфликтов от выраженности агрессивного поведения. Результаты могут быть использованы в практической работе со студентами для повышения конфликтологической компетентности.

Ключевые слова: способы разрешения конфликтов, формы агрессивного поведения, студенты педагогического вуза, профиль образования.
\end{abstract}

D.V. Kashirsky, M.A. Maletina

\title{
TEACHER STUDENTS CONFLICTS RESOLUTION DEPENDING ON THEIR PROFILE OF THE EDUCATION AND TENDENCIES TO VARIOUS FORMS OF AGGRESSIVE BEHAVIOUR
}

\begin{abstract}
The paper presents the results of research the resolution of conflicts teacher students depending on their profile of the education and forms of aggression. The study was conducted at the Altai State Pedagogical University. The sample was based on students from Institute of Psychology and Pedagogics and Faculty of Physical Education and Sport those between 18 and 22 years of age. The study found no statistically significant difference in conflict resolution and forms of aggression between the two compared groups. The relation between resolution of conflicts and forms of aggression was identified $(\mathrm{N}=50)$. The results of the study might be useful for improvement of the student's competence in conflict resolution.

Key words: conflict resolution, forms of aggression, teacher students, profile of the education.
\end{abstract}

Проблема конфликта и конфликтного поведения - одна из центральных междисциплинарных проблем, которая не раз становилась предметом всестороннего анализа в философии (Г.В.Ф. Гегель, И. Кант, К. Маркс и др.), социологии (М. Вебер, М. Дойч, Г. Зиммель, К. Томас и др.), психологии (А. Адлер, К. Левин, 3. Фрейд, Э. Фромм, М. Шериф и др.) и других областях знания. Умение разрешать конфликты, используя подходящие стратегии их урегулирования - неотъемлемое условие социального взаимодействия людей и эффективного функционирования общества в целом. Высокий уровень конфликтологической компетентности важен в работе психологов, педагогов, юристов, работников сферы обслуживания и т. д., то есть людей, работающих в сфере профессий типа «человек - человек». Поэтому на стадии вузовского обучения крайне важно сформировать у будущих специалистов умения в области разрешения конфликтных ситуаций.

Проблеме конфликтного поведения посвящены многие учебники, учебные пособия и монографии (см., например, [1-13] и др.), научные статьи в периодических изданиях [14-17], ряд исследований, в том числе диссертационных, посвящены изучению стратегий конфликтного поведения в конфликте студенческой молодежи, в том числе учащихся педагогических вузов $[16,18,19]$ и др. Однако, 
несмотря на интерес психологов к проблеме конфликтного поведения и ее детальную, как может показаться на первый взгляд, разработанность в психологической науке и практике, данная проблема продолжает сохранять свою актуальность, как в научном, так и в прикладном плане. В настоящее время не является полностью решенной проблема факторов, условий и механизмов конфликтного поведения. Высокой значимостью обладают исследования, направленные на изучение личностных предпосылок конфликтогенного поведения в молодежной среде, в том числе у студентов педагогических вузов различных профилей обучения. Есть основания полагать, что одним из дескрипторов для реализации различных стратегий разрешения конфликтов является склонность субъекта к той или иной форме агрессивного поведения.

В основу проведенного нами исследования положены следующие гипотезы:

1. У студентов педагогического вуза различных образовательных профилей способы разрешения конфликтов характеризуются разной степенью выраженности.

2. Выраженность различных способов разрешения конфликтов связана с особенностями проявления агрессивности у студентов.

Методы исследования: тестирование с помощью опросника «Стратегии поведения в конфликте» К. Томаса - Р. Килманна в адаптации Н.В. Гришиной [20] и опросника агрессивности Басса - Дарки в адаптации А.К. Осницкого [21]. В качестве математико-статистических методов использованы: W-критерий Шапиро - Уилка, корреляционный анализ (К. Пирсон, Ч. Спирмен), критерии сравнения (t-Стьюдента для независимых выборок, M-W-Манна -Уитни), множественный регрессионный анализ (MRA), моделирование структурными уравнениями (SEM) в AMOS.

Выборка. В исследовании приняли участие 25 студентов 1-2 курсов института психологии и педагогики, возраст - 18-22 (M = 19,6, SD = 0,86) и 25 студентов 2 курса института физической культуры и спорта $(\mathrm{M}=19,9, \mathrm{SD}=0,64)$ Алтайского государственного педагогического университета, всего 50 чел.

Способы разрешения конфликтов в зависимости от профиля образования студентов. В табл. 1 представлены результаты исследования способов разрешения конфликтов студентами института психологии и педагогики (ИПиП) с помощью методики К. Томаса - Р. Килманна.

Полученные результаты указывают на то, что ведущей стратегией студентов ИПиП при разрешении конфликтов является избегание, ее используют 30 \% испытуемых. Такие студенты обычно игнорируют конфликтную ситуацию, делают вид, что ее вовсе не существует.

Таблица 1

Стратегии поведения в конфликте студентов ИПиП

\begin{tabular}{|c|l|c|}
\hline № & \multicolumn{1}{|c|}{$\begin{array}{c}\text { Способы разрешения } \\
\text { конфликтов }\end{array}$} & Выраженность, \% \\
\hline 1 & Конфронтация & 23,3 \\
\hline 2 & Сотрудничество & 16,7 \\
\hline 3 & Компромисс & 6,7 \\
\hline 4 & Избегание & 30,0 \\
\hline 5 & Приспособление & 23,3 \\
\hline
\end{tabular}

По 23,3 \% студентов ИПиП используют в ситуации столкновения интересов с другими людьми такие стратегии поведения, как конфронтация и приспособление. Поведение студентов, использующих в конфликте стратегию конфронтации, направлено на удовлетворение собственных интересов без учета мнения другой стороны, а иногда и в ущерб ей. Они добиваются удовлетворения своих притязаний и стараются убедить или принудить другую сторону пойти на уступки. Студенты, склонные разрешать конфликты путем приспособления, готовы пожертвовать своими интересами, целями и уступить другому человеку ради того, чтобы избежать конфликта.

Сотрудничество как стратегию разрешения конфликтов используют 16,7 \% студентов ИПиП. Такие студенты обычно нацелены на удовлетворение интересов обеих сторон, как правило, стремятся к поиску решения, которое полностью удовлетворит всех участников конфликта.

Всего лишь 6,7 \% студентов ИПиП в конфликте ориентированы на поиск компромиссного решения. Они не стараются добиться своей цели за счет других и не отказываются от собственных интересов, а ищут наилучший вариант решения конфликтной ситуации, идя на взаимные уступки, стараясь удовлетворить интересы своей стороны и стороны оппонента.

В табл. 2 представлены результаты исследования выраженности способов разрешения конфликтов студентами ИФКиС.

На основе полученных данных можно сделать вывод о том, что 34,5 \% студентов ИФКиС выбирают избегание как доминирующую позицию при разрешении конфликтов. Эти студенты стараются переносить обсуждение конфликтных вопросов на потом. Они не пытаются отстаивать собственные интересы, но и не учитывают интересы других людей.

Стратегию «Компромисс» применяют 27,6 \% студентов данного института. Для них характерно стремление к частичному удовлетворению интересов каждой из сторон конфликта. 
Таблица 2

Выраженность способов разрешения конфликтов у студентов ИФКиС

\begin{tabular}{|c|l|c|}
\hline № & $\begin{array}{c}\text { Способы разрешения } \\
\text { конфликтов }\end{array}$ & Выраженность, \% \\
\hline 1 & Конфронтация & 13,8 \\
\hline 2 & Сотрудничество & 13,8 \\
\hline 3 & Компромисс & 27,6 \\
\hline 4 & Избегание & 34,5 \\
\hline 5 & Приспособление & 10,3 \\
\hline
\end{tabular}

Конфронтацию и сотрудничество как способы разрешения конфликтов используют по 13,8 \% студентов ИФКиС. Эти студенты стремятся добиться удовлетворения своих интересов в ущерб интересам других людей. Они уверены, что выйти победителем из конфликта может только одна из сторон, и победа одного участника неизбежно означает поражение другого. Они будут настаивать на своем, а мнения других людей ими, скорее всего, не будут приняты во внимание. Студенты, разрешающие конфликты путем сотрудничества, стремятся, чтобы в выигрыше оказались все заинтересованные стороны. Они не просто учитывают позиции других участников, но пытаются добиться того, чтобы и другая сторона также достигла удовлетворения при разрешении конфликта.

Стратегию «Приспособление» в конфликте используют 10,3 \% студентов ИФКиС. Данная категория людей готова пожертвовать своими интересами, сделать так, чтобы конфликт вообще не состоялся.

Проведем сравнительный анализ выраженности различных способов разрешения конфликтов у студентов рассматриваемых институтов. Представим полученные результаты более наглядно (рис. 1).

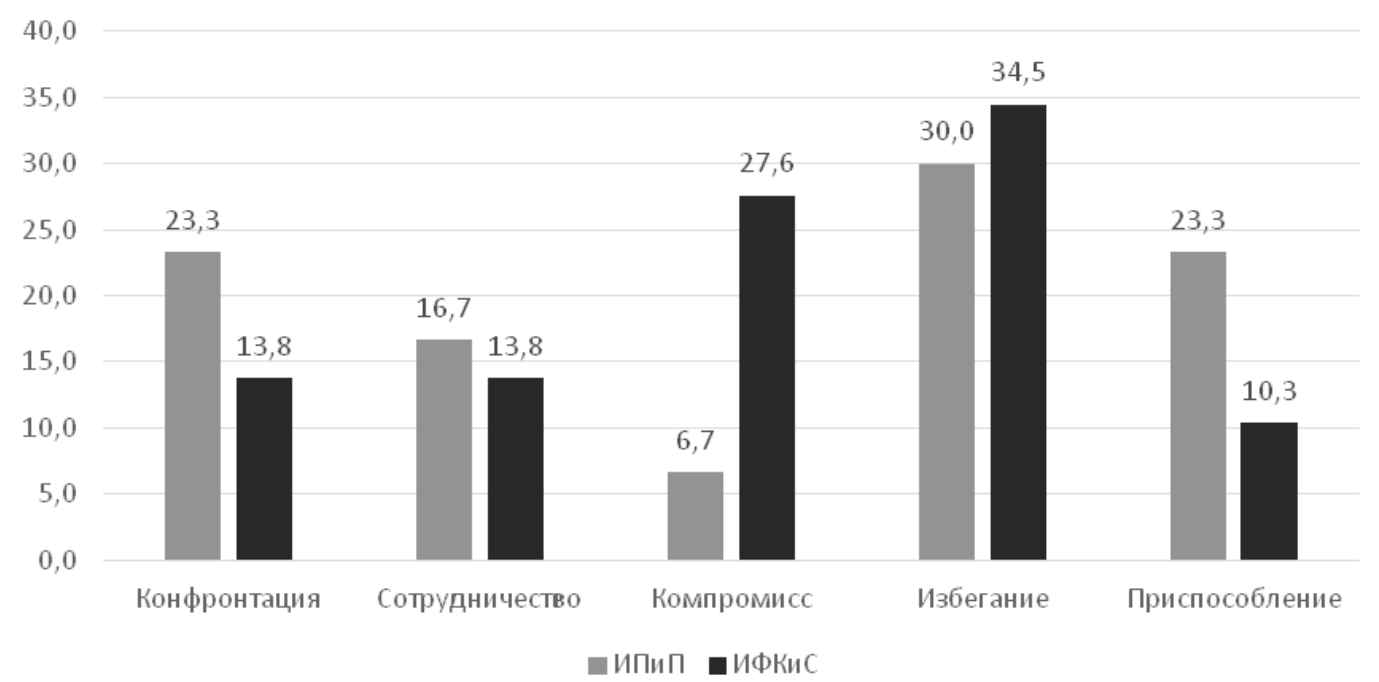

Рис. 1. Способы разрешения конфликтов студентами ИПиП и ИФКиС, \%

Анализ рис. 1 приводит к выводу, что такой способ разрешения конфликтов, как конфронтация, чаще используется студентами ИПиП, чем ИФКиС. Студенты ИПиП проявляют большую активность при отстаивании собственных интересов, применяют все доступные средства для достижения поставленных целей, начиная от убеждения оппонентов и заканчивая давлением на них и принуждением поменять исходную точку зрения.

Помимо этого, визуальный анализ рис. 1 показывает, что студенты ИПиП, в сравнении со студентами ИФКиС, чаще при разрешении конфликта прибегают к сотрудничеству, т. е. проявляют большую активность в поиске решения, удовлетворяющего всех участников взаимодействия. Они используют открытый обмен мнениями и вместе с другими участниками конфликта вырабатывают общее решение.
В свою очередь студенты ИФКиС, в сравнении со студентами ИПиП, чаще используют компромисс при разрешении конфликтов, находя решения за счет взаимных уступок. Для них характерна ориентация на выработку решения, устраивающего все стороны конфликта, когда особенно никто не выигрывает, но и не теряет.

Наряду с этим студенты ИФКиС в большей степени пользуются таким способом разрешения конфликтов, как избегание. Как правило, такой способ поведения в конфликте весьма эффективен в том случае, когда субъект не хочет отстаивать свои права или сотрудничать для выработки общего решения, поэтому он воздерживается от высказывания своей позиции и уклоняется от спора. Нередко такие люди хотят просто уйти от всякой ответственности за принятые решения. 
На рис. 1 также видно, что приспособление как способ разрешения конфликтов в большей степени используют студенты ИПиП, нежели ИФКиС. Действия субъекта в данном случае направлены на сохранение или восстановление благоприятных отношений с оппонентом путем сглаживания разногласий за счет собственных интересов.

Следует, однако, заметить, что проведенные нами сравнения студентов разных профилей образования построены лишь на основании визуального анализа столбиковых диаграмм, поэтому могут носить случайный характер. Для более корректного сопоставления между собой степени выраженности различных способов разрешения конфликтов студентов рассматриваемых институтов должны быть использованы методы не описательной, а индуктивной статистики, что и будет нами выполнено далее.

Как известно, для статистической проверки гипотезы о различиях между двумя выборками по степени выраженности какого-либо признака может быть использован $\mathrm{t}$-критерий Стьюдента для независимых выборок или его непараметрический аналог $\mathrm{M}-\mathrm{W}$-критерий Манна - Уитни. Однако вначале следует оценить возможность использования того или иного критерия: выполнить проверку нормальности распределения каждого признака, который будет участвовать в анализе, а также дисперсий сравниваемых показателей на гомогенность.

Оценка нормальности распределения. С помощью W-критерия Шапиро - Уилка мы выяснили, что распределение признака в обеих группах испытуемых по всем измерительным шкалам методики Томаса, за исключением шкалы «конфронтация», значимо не отличается от нормального (табл. 3), что указывает на возможность использования $\mathrm{t}$-критерия Стьюдента для всех шкал методики Томаса - Килманна за исключением шкалы конфронтации, для которой может быть использован $\mathrm{M}$-W-критерий Манна - Уитни.

Таблица 3

Оценка нормальности распределения (критерий Шапиро - Уилка)

\begin{tabular}{|l|c|c|}
\hline \multicolumn{1}{|c|}{$\begin{array}{c}\text { Способы разрешения } \\
\text { конфликта }\end{array}$} & W & p-value \\
\hline Конфронтация & 0,951 & $0,037^{*}$ \\
\hline Сотрудничество & 0,974 & 0,329 \\
\hline Компромисс & 0,959 & 0,080 \\
\hline Избегание & 0,970 & 0,242 \\
\hline Приспособление & 0,983 & 0,680 \\
\hline
\end{tabular}

${ }^{*}-p \leq 0,05$.
Гомогенность дисперсий. Далее с помощью критерия Ливиня была произведена оценка однородности дисперсий в сравниваемых выборках по каждому признаку (табл. 4).

Таблица 4

Оценка однородности дисперсий (критерий Ливиня)

\begin{tabular}{|l|c|c|c|c|}
\hline $\begin{array}{c}\text { Способы } \\
\text { разрешения } \\
\text { конфликта }\end{array}$ & $\mathbf{F}$ & $\mathbf{d f}_{\mathbf{1}}$ & $\mathbf{d f}_{2}$ & $\mathbf{p}$-value \\
\hline Конфронтация & 3,89 & 1 & 48 & 0,054 \\
\hline Сотрудничество & 0,27 & 1 & 48 & 0,605 \\
\hline Компромисс & 4,23 & 1 & 48 & $0,045^{\star}$ \\
\hline Избегание & 0,005 & 1 & 48 & 0,943 \\
\hline Приспособление & 1,58 & 1 & 48 & 0,214 \\
\hline
\end{tabular}

${ }^{*}-p \leq 0,05$.

Проведенный анализ показывает, что для таких шкал методики К. Томаса - Р. Килманна, как сотрудничество, избегание и приспособление, показатели дисперсий в сравниваемых выборках равны между собой. Для шкалы компромисса требование однородности дисперсий не выполняется $(\mathrm{p} \leq 0,05)$, т. е. в данном случае нарушено условие использования t-критерия Стьюдента. Кроме этого, для шкалы «конфронтация» значение статистики Ливиня близко к критическому $(\mathrm{p} \leq 0,054)$, что также указывает на ограничения в использовании параметрических методов. Поэтому $\mathrm{M}-\mathrm{W}$-критерий Манна - Уитни должен быть рассчитан для шкал компромисса и конфронтации. В табл. 5 представлены результаты статистических сопоставлений.

Таблица 5

Результаты оценки значимости различий в способах разрешения конфликтов студентами ИПиП и ИФКиС

\begin{tabular}{|l|l|c|c|c|}
\hline $\begin{array}{c}\text { Тип поведения } \\
\text { в конфликте }\end{array}$ & \multicolumn{1}{|c|}{ Критерий } & Statistic & df & p-value \\
\hline Конфронтация & $\begin{array}{l}\text { М-W-Манна - } \\
\text { Уитни }\end{array}$ & 263 & - & 0,334 \\
\hline Сотрудничество & t-Стьюдента & $-0,974$ & 48,0 & 0,335 \\
\hline Компромисс & $\begin{array}{l}\text { М-W-Манна - } \\
\text { Уитни }\end{array}$ & 268 & - & 0,377 \\
\hline Избегание & t-Стьюдента & $-0,243$ & 48,0 & 0,809 \\
\hline Приспособление & t-Стьюдента & $-0,495$ & 48,0 & 0,623 \\
\hline
\end{tabular}

Из данных табл. 5 видно, что между студентами института психологии и педагогики и института физической культуры и спорта значимых различий в выраженности определенных способов разрешения 
конфликтов не обнаружено. Таким образом, первая гипотеза нашего исследования не подтвердилась. Возможно, выборки различаются качественными особенностями сравниваемых показателей. Однако ответ на этот вопрос будет являться предметом нашей дальнейшей работы.

Способы разрешения конфликтов в зависимости от форм агрессивного поведения студентов. Для проверки второй гипотезы исследования о взаимосвязи между способами поведения в конфликте и проявлениями агрессии у студентов может быть использован корреляционный анализ: параметрический (по К. Пирсону) или непараметрический (по Ч. Спирмену). Оценим возможность их использования. Для этого проведем тест нормальности Шапиро - Уилка для шкал методики Басса - Дарки (табл. 6). Заметим, что для теста К. Томаса - Р. Килманна такая работа нами была проведена ранее (см. табл. 3).

Таблица 6

Оценка нормальности распределения (критерий Шапиро - Уилка)

\begin{tabular}{|l|c|c|}
\hline \multicolumn{1}{|c|}{ Формы агрессивного поведения } & $\mathbf{W}$ & p-value \\
\hline Физическая агрессия & 0,979 & 0,493 \\
\hline Косвенная агрессия & 0,977 & 0,424 \\
\hline Раздражительность & 0,988 & 0,903 \\
\hline Негативизм & 0,962 & 0,113 \\
\hline Обида & 0,965 & 0,148 \\
\hline Подозрительность & 0,970 & 0,226 \\
\hline Вербальная агрессия & 0,955 & 0,053 \\
\hline Чувство вины & 0,970 & 0,225 \\
\hline
\end{tabular}

Результаты, представленные в табл. 6, указывают на то, что данные по шкалам методики Басса - Дарки подчинены закону нормального распределения. Полученный результат позволяет использовать для этих шкал коэффициент Пирсона, конечно, при условии, что сопоставляемый с ними признак (шкала теста Томаса - Килманна) также имеет гауссово распределение. Однако прежде чем переходить к выполнению корреляционного анализа, сравним студентов ИПиП и ИФКиС между собой по степени выраженности различных форм агрессивного поведения. В результате проведенных вычислений установлено, что критерий Стьюдента для независимых выборок не выявил статистически значимых различий между выборками ни по одному показателю (p > 0,10). Таким образом, студенты, обучающиеся в разных институтах, не имеют выраженных различий не только в способах разре- шения конфликтов, что было показано выше, но и в склонностях к различным формам агрессивного поведения. Так как сравниваемые выборки являются однородными по сопоставляемым показателям, корреляционный анализ будет проведен нами на общей выборке студентов $(\mathrm{N}=50)$.

Корреляционный анализ. В корреляционной матрице (табл. 7) представлены только статистически значимые коэффициенты корреляции между шкалами опросника К. Томаса - Р. Килманна и Басса - Дарки $(\mathrm{N}=50)$.

Таблица 7

Результаты корреляционного анализа между способами разрешения конфликтов и типами агрессивного поведения у студентов $(\mathrm{N}=50)$

\begin{tabular}{|c|c|c|c|c|}
\hline Переменные & $\begin{array}{c}\text { Физиче- } \\
\text { ская } \\
\text { агрессия }\end{array}$ & $\begin{array}{c}\text { Раздра- } \\
\text { житель- } \\
\text { ность }\end{array}$ & $\begin{array}{c}\text { Вер- } \\
\text { бальная } \\
\text { агрессия }\end{array}$ & $\begin{array}{c}\text { Чув- } \\
\text { ство } \\
\text { вины }\end{array}$ \\
\hline Конфронтация & $0,342^{*}$ & - & $0,447^{* *}$ & - \\
\hline Сотрудничество & $-0,333^{*}$ & $-0,302^{*}$ & - & $0,283^{*}$ \\
\hline Приспособление & - & - & $-0,375^{* *}$ & - \\
\hline
\end{tabular}

${ }^{*}-p \leq 0,05,{ }^{* *}-p \leq 0,01$.

Из данных табл. 7 видно, что между исследуемыми параметрами существуют как прямые, так и обратные корреляционные связи. Так, конфронтацию как способ разрешения конфликтов выбирают студенты с более высоким уровнем физической и вербальной агрессии; сотрудничество характерно для тех испытуемых, у кого, напротив, менее выражена склонность к физической агрессии и раздражительности, но в среднем более высокие показатели чувства вины (в терминологии Басса - Дарки этим качеством характеризуются совестливые и мнительные натуры); позиция приспособления в конфликте свойственна студентам педагогического университета, которых отличает более низкий уровень вербальной агрессии.

Множественный регрессионный анализ. Результаты корреляционного анализа не дают возможности делать выводы о наличии причинно-следственных связей между коррелирующими признаками, однако позволяют сформулировать ряд гипотез, касающихся зависимости некоторых способов разрешения конфликтов студентами педагогического вуза от выраженности у них тех или иных форм агрессивного поведения. Кроме того, наличие некоторого множества значимых, но «разрозненных» парных корреляций совсем не гарантирует существования некоторой структуры связей между изучаемыми признаками. Поэтому статистический 
анализ должен быть продолжен. Так, исходя из корреляционного анализа (табл. 7), можно высказать предположение о том, что к конфронтации как способу разрешения конфликтов преимущественно склоняются студенты с выраженной физической и вербальной агрессией. Проверим это с помощью множественного регрессионного анализа (MRA), где в качестве предикторов выступят названные формы агрессивного поведения, а зависимой переменной - стратегия конфронтации.

В табл. 8 представлены общие результаты MRA. Из этой таблицы видно, что коэффициент множественной корреляции (R) для расчетной модели оказался статистически значимым, поэтому данная модель может быть содержательно интерпретирована. Коэффициент множественной детерминации $\mathrm{R} 2=0,262$ указывает, что регрессионная модель объясняет около 26 \% дисперсии зависимой переменной.

Таблица 8

Оценка качества регрессионной модели

\begin{tabular}{|c|c|c|c|c|c|c|}
\hline Модель & $\mathbf{R}$ & $\mathbf{R}^{\mathbf{2}}$ & $\mathbf{F}$ & $\mathbf{d f}_{\mathbf{1}}$ & $\mathbf{d f}_{\mathbf{2}}$ & $\mathbf{p}$-value \\
\hline 1 & 0,512 & 0,262 & 8,36 & 2 & 47 & $<0,001$ \\
\hline
\end{tabular}

* Зависимая переменная - конфронтация как способ разрешения конфликтов, независимые переменные - физическая и вербальная агрессия.

Табл. 9 содержит нестандартизированные коэффициенты регрессии (В), величины их стандартных ошибок (SE), значения статистик Стьюдента, а также соответствующие им ожидаемые уровни значимости (p-value).

Таблица 9 Оценка значимости регрессионных коэффициентов

\begin{tabular}{|l|c|c|c|c|}
\hline \multicolumn{1}{|c|}{ Предикторы } & B & SE & t & p-value \\
\hline Константа & $-0,9114$ & 1,3684 & $-0,666$ & 0,509 \\
\hline Физическая агрессия & 0,0177 & 0,0218 & 0,815 & 0,419 \\
\hline Вербальная агрессия & 0,0500 & 0,0153 & 3,268 & 0,002 \\
\hline
\end{tabular}

* Зависимая переменная - конфронтация как способ разрешения конфликта.

Данные табл. 9 позволяют дать статистическую оценку полученных регрессионных коэффициентов. Так, из таблицы видно, что переменная «физическая агрессия» имеет незначимый регрессионный коэффициент, несмотря на то, что значимо коррелирует с зависимой переменной (табл. 7). Вероятно, это связано с тем, что данная переменная высоко коррелирует с другим дескриптором данной регрес- сионной модели - вербальной агрессией $(\mathrm{r}=0,43$, $\mathrm{p} \leq 0,002)$, что вполне могло стать причиной снижения ее В-коэффициента. Поэтому физическая агрессия не будет использоваться нами для предсказания значений зависимой переменной, иначе говоря, будет исключена из регрессионной модели, т. е., по данным MRA, единственной выявленной нами «причиной», лежащей в основе стратегии конфронтации при разрешении конфликтов у студентов педагогического университета, является высокий уровень вербальной агрессии. Перерасчет параметров регрессионной модели после исключения из нее дескриптора «физическая агрессия» позволил установить следующие характеристики модели: $\mathrm{R}=0,502, \mathrm{R} 2=0,25, \mathrm{~F}=16,18, \mathrm{p} \leq 0,001$. Заметим, однако, что только 1/4 часть всей вариативности значений переменной «конфронтация» обусловлена влиянием вербальной агрессии, тогда как остальные 75 \%, очевидно, вызваны другими переменными, не отраженными в дизайне данного исследования.

Далее, на основании корреляционной матрицы (табл. 7) была построена еще одна регрессионная модель и также осуществлена проверка ее состоятельности с помощью MRA. Теперь в качестве предикторов выступили такие формы агрессивного поведения, как физическая агрессия, раздражительность и чувство вины (совестливость, мнительность), а зависимой переменной являлась стратегия сотрудничества при разрешении конфликтов.

В табл. 10 представлены общие результаты MRA, в целом довольно похожие на те, которые были получены для первой регрессионной модели. Так, коэффициент множественной корреляции (R) вновь оказался статистически значимым, поэтому данная модель может быть содержательно интерпретирована, а коэффициент множественной детерминации $\mathrm{R} 2=0,266$, указывает на то, что регрессионная модель объясняет около 27 \% изменчивости зависимой переменной.

Таблица 10

Оценка качества регрессионной модели

\begin{tabular}{|c|c|c|c|c|c|c|}
\hline Модель & $\mathbf{R}$ & $\mathbf{R}^{\mathbf{2}}$ & $\mathbf{F}$ & $\mathbf{d f}_{\mathbf{1}}$ & $\mathbf{d f}_{\mathbf{2}}$ & $\mathbf{p}$-value \\
\hline 2 & 0,516 & 0,266 & 5,56 & 3 & 46 & 0,002 \\
\hline
\end{tabular}

* Зависимая переменная - сотрудничество как способ разрешения конфликтов, независимые переменные - физическая и вербальная агрессия.

Данные табл. 11 указывают на то, что все регрессионные коэффициенты во второй модели статистически значимы. Таким образом, разрешение конфликтов путем сотрудничества с оппонентами 
используют студенты, не склонные к раздражительности и физической агрессии, но отличающиеся в терминологии Басса - Дарки выраженным чувством вины (совестливость, мнительность). При этом следует заметить, что данные предикторы так же объясняют лишь $1 / 4$ часть общей вариативности зависимой переменной, в то время как остальные 75 \% «причин», лежащих в основе использования студентами педвуза стратегии сотрудничества при разрешении конфликтов, в исследовании выявлены не были. Для поиска этих дескрипторов необходимо проведение дополнительного исследования.

Таблица 11 Оценка значимости регрессионных коэффициентов ${ }^{*}$

\begin{tabular}{|l|c|c|c|c|}
\hline \multicolumn{1}{|c|}{ Предикторы } & B & SE & t & p-value \\
\hline Константа & 7,0646 & 0,87910 & 8,04 & $<0,001$ \\
\hline Физическая агрессия & $-0,0221$ & 0,01017 & $-2,17$ & 0,035 \\
\hline Раздражительность & $-0,0207$ & 0,00864 & $-2,40$ & 0,020 \\
\hline Чувство вины & 0,0210 & 0,00929 & 2,25 & 0,029 \\
\hline
\end{tabular}

* Зависимая переменная - сотрудничество как способ разрешения конфликтов

Таким образом, что вторая гипотеза исследования подтверждена: выраженность различных стратегий разрешения конфликтов связана с особенностями проявления агрессивности у студентов. Можно сказать, что в основе конфронтации лежит выраженная вербальная агрессия; сотрудничество возможно при низких уровнях раздражительности и физической агрессии, но высоких показателях чувства вины (совестливость, мнительность); тогда как приспособление (табл. 7) характерно для студентов, отличающихся низкой вербальной агрессией.

Найденные зависимости, безусловно, позволяют глубже понять отношения между стратегиями, используемые студентами педагогического университета, при разрешении конфликтов и проявлениями агрессивности. Однако установлены они по отдельности, то есть статистически обоснованы в каждом из трех случаев изолированно от двух других. Для того, чтобы доказать существование структуры связей между изучаемыми признаками, необходимо провести многомерный корреляционный анализ, одним из вариантов которого является метод моделирования структурными уравнениями (SEM).

Структурное моделирование. На основе результатов корреляционного и регрессионного анализа была построена структурная модель взаимосвязи способов разрешения конфликтов и выраженности различных форм агрессивного поведения у студентов педагогического вуза ( $\mathrm{N}=50)$. Проверим адекватность этой модели эмпирическим данным с помощью метода моделирования структурными уравнениями (SEM). Представим нашу гипотетическую модель в виде блок-схемы в среде AMOS (рис. 2).

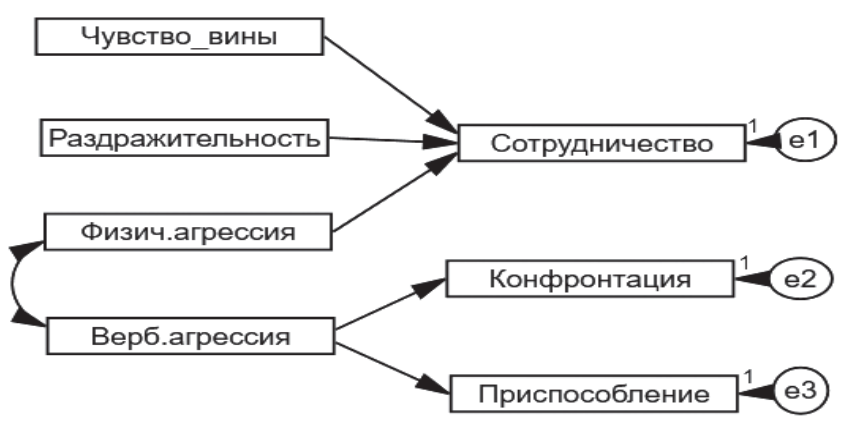

Рис. 2. Априорная структурная модель зависимости способов разрешения конфликтов от выраженности различных форм агрессивного поведения у студентов педвуза

Модель содержит 3 наблюдаемых эндогенных переменных, фигурирующих в корреляционной матрице, а также выступающих в качестве зависимых переменных в множественном регрессионном анализе: «Сотрудничество», «Конфронтация» и «Приспособление». Источниками специфичности этих переменных являются соответствующие ошибки, обозначенные в модели как е1, e2, е3 (по количеству наблюдаемых эндогенных переменных). Наряду с этим в структурную модель входят 4 наблюдаемых экзогенных переменных (фактора), также отраженных в корреляционной матрице и/или выступающих в качестве независимых переменных или дескрипторов (влияние которых статистически значимо) в моделях проведенного ранее множественного регрессионного анализа: «Чувство вины», «Раздражительность», «Физическая агрессия», «Вербальная агрессия». На блок-схеме отражена также найденная ранее корреляционная связь между проявлениями вербальной и физической агрессии.

Далее проведена оценка данной модели, в результате чего было установлено, что критический коэффициент для многомерного эксцесса оказался значительно меньше пяти (c.r. = -0,475), т. е. условие многомерной нормальности переменных соблюдено. Кроме этого, была проведена процедура освобождения фиксированных параметров в модели с целью уменьшения значения $\chi 2$ за счет добавления в модель связи между ошибками е2 и е3, а также эндогенными переменными. После 
этого были получены следующие индексы соответствия теоретической модели эмпирическим данным: $\chi 2=8,584, \mathrm{df}=9, \mathrm{p}=0,954 ; \chi 2 / \mathrm{df}=0,954$, $\mathrm{CFI}=0,998, \mathrm{RMSEA}=0,001$. Эти показатели указывают на очень хорошее соответствие тестируемой модели эмпирическим данным.

На рис. 3 представлена апостериорная структурная модель зависимости способов разрешения конфликта от выраженности у студентов педагогического университета различных форм агрессивного поведения.

Отметим, что все регрессионные коэффициенты, полученные в модели, статистически значимы (табл. 12).

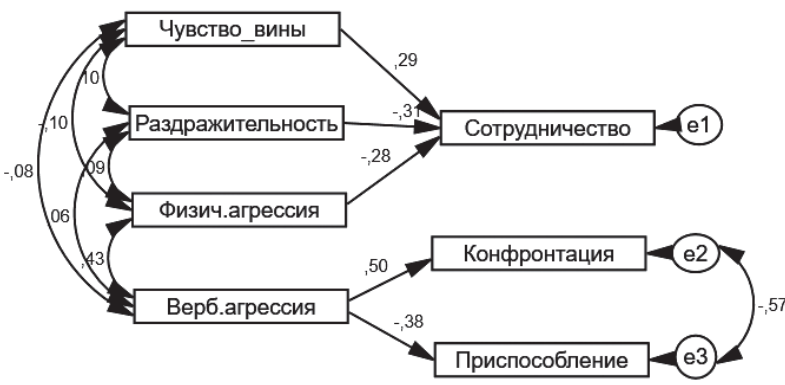

Рис. 3. Апостериорная структурная модель зависимости способов разрешения конфликтов от выраженности различных форм агрессивного поведения у студентов педвуза

Оценка значимости регрессионных коэффициентов

\begin{tabular}{|lcl|c|c|c|c|}
\hline \multicolumn{2}{|c|}{ Регрессионные коэффициенты } & B & S.E. & C.R. & p-value \\
\hline Сотрудничество & $<---$ & Чувство вины & 0,021 & 0,009 & 2,327 & 0,020 \\
\hline Сотрудничество & $<---$ & Раздражительность & $-0,021$ & 0,008 & $-2,479$ & 0,013 \\
\hline Сотрудничество & $<---$ & Физическая агрессия & $-0,022$ & 0,010 & $-2,242$ & 0,025 \\
\hline Конфронтация & $<---$ & Вербальная агрессия & 0,055 & 0,014 & 4,064 & $* *$ \\
\hline Приспособление & $<---$ & Вербальная агрессия & $-0,030$ & 0,011 & $-2,832$ & 0,005 \\
\hline
\end{tabular}

Таким образом, мы можем сделать вывод о том, что гипотетическая структурная модель была нами успешно верифицирована.

Проведенное исследование позволило сформулировать следующие основные выводы:

Установлено, что преобладающей стратегией при разрешении конфликтов студентами института психологии и педагогики педагогического университета является избегание, а наименее приоритетной - компромисс. Большинство студентов института физической культуры и спорта педагогического университета при разрешении конфликтов также чаще всего используют избегание, а в меньшей степени склонны к приспособлению. Исследование не выявило различий между студентами разных профилей образования в преобладании той или иной стратегии при разрешении конфликтов, а также выраженности различных форм агрессивного поведения.
Найдена зависимость между способами разрешения конфликтов и формами агрессивного поведения у студентов педагогического вуза. Установлено, что стратегия сотрудничества при разрешении конфликтов чаще используется студентами с низким уровнем раздражительности и физической агрессии, а также выраженным чувством вины, что выражается в совестливости и мнительности этих натур. В основе стратегий конфронтации и приспособления лежит уровень вербальной агрессии: студенты с выраженной вербальной агрессией склонны к конфронтации в конфликте, в то время как использование в качестве способа разрешения конфликтов стратегии приспособления связано с низким уровнем вербальной агрессии.

Полученные результаты могут быть использованы для повышения конфликтологической компетентности студентов педагогических вузов.

\section{Библиографический список}

1. Анцупов А. Я., Шипилов А. И. Конфликтология: учебник для вузов. 3-е изд. СПб.: Питер, 2008. 591 с.

2. Буртовая Е. В. Конфликтология: учеб. пособие. М.: Юнити, 2002. 512 с.

3. Вишнякова Н. Ф. Конфликтология: учеб. пособие. Минск: Университетское, 2002. 551 с.

4. Ворожейкин И. Е. Конфликтология: учебник для вузов. М.: ИНФРА-М, 2002. 301 с.

5. Дмитриев А. В. Конфликтология: учеб. пособие. М.: Гардарики, 2000. 320 с.

6. Емельянов С. М. Практикум по конфликтологии. 3-е изд., перераб. и доп. СПб.: Питер, 2003. 384 с.

7. Козырев Г. И. Введение в конфликтологию: учебное пособие для студентов высших учебных заведений. М.: ВЛАДОС, 2001. 176 с. 
8. Конфликтология: учебник / под ред. А. С. Кармина. СПб.: Лань, 1999. 448 с.

9. Конфликтология: учебник / А. Я. Кибанов [и др.]; под ред. А. Я. Кибанова. М.: ИНФРА-М, 2009.240 с.

10. Конфликты: Борьба, взаимодействие, сотрудничество / под ред. д-ра пед. наук, проф. Г. М. Потанина. М.: Белгород, 1997. 342 с.

11. Лютова С. Н. Основы психологии и коммуникативной компетенции: курс лекций. М.: МГИмО-Университет, 2007. $268 \mathrm{c}$. $64 \mathrm{c}$.

12. Парфёнова Г. Л. Конфликтология: учебно-метод. пособие. 2-е изд., перераб. и доп. Барнаул: БГпУ, 2008.

13. Скотт Д. Г. Конфликты и пути их разрешения. Киев: Внешторгиздат, 1991. 430 с.

14. Багаева В. В. Стратегии поведения в конфликте // Сибирский торгово-экономический журнал. 2015. № 2. C. 91-92.

15. Демчук А. Л. Особенности принятия решения в конфликтных ситуациях // Пространство и Время. 2015. № 2. C. 1-8.

16. Карабущенко Н. Б. Влияние психологической дистанции на конфликтные ситуации в студенческой среде: дис. ... канд. психол. наук. Ставрополь, 2002. 220 с.

17. Профилактика и разрешение деструктивных явлений в конфликте / Н. И. Заиченко [и др.] // Педагогика и психология образования. 2010. № 1. С. 160-187.

18. Володина С. А. Приоритетные стратегии поведения в конфликте студентов педагогического вуза // Преподаватель XXI век. 2014. № 1-1. С. 186-190.

19. Петрова Е. Г. Особенности выбора стратегии поведения в конфликте в студенческой среде // Вестник Таганрогского института имени А. П. Чехова. 2015. № 2. С. 283-287.

20. Гришина Н. В. Психология конфликта. 2-е изд. СПб.: Питер, 2008. 544 с.

21. Фетискин Н. П., Козлов В. В., Мануйлов Г. М. Социально-психологическая диагностика развития личности и малых групп. М.: Институт психотерапии, 2002. 490 с. 